\title{
Predicting the variation of the exit temperature with the initial billet temperature during extrusion to produce an AZ31 profile
}

\author{
G. Liu • J. Zhou • J. Duszczyk
}

Received: 13 October 2008 / Accepted: 27 January 2009/Published online: 20 February 2009

(C) The Author(s) 2009. This article is published with open access at Springerlink.com

\begin{abstract}
The extrusion process to produce a cross-shaped profile of a wrought magnesium alloy AZ31 was simulated to predict the exit temperature as a function of the initial billet temperature. Three-dimensional FE simulation revealed the evolutions of temperature and extrusion pressure during the process. The initial billet temperature was found to have a stronger influence on the breakthrough pressure than ram speed. It also played an important role in determining the exit temperature and the temperature rise during the process, especially when ram speed was high. At a given ram speed, the relationship between the temperature rise and the initial billet temperature was found to be linear. Such a relationship could be used as guidelines to optimize the extrusion process and to maximize its throughput.
\end{abstract}

Keywords Finite element method - Computer simulation . Wrought magnesium alloys $\cdot$ Extrusion

\section{Introduction}

The extrusion of a wrought magnesium alloy is a thermally activated process [1]. The key to controlling the process lies in the understanding of the relationship between the

\section{G. Liu}

School of Materials Science and Engineering,

Harbin Institute of Technology,

Harbin 150001, China

J. Zhou $(\bowtie) \cdot$ J. Duszczyk

Department of Materials Science and Engineering,

Delft University of Technology,

Mekelweg 2,

2628 CD Delft, The Netherlands

e-mail: J.Zhou@tudelft.nl extrusion conditions and the thermomechanical response of the alloy to hot deformation. Although there are many factors directly or indirectly governing the extrusion conditions, for a given die to produce a profile with a certain cross-section shape, billet temperature and ram speed are the two primary process variables [2]. The response of the billet material under a given extrusion condition is reflected in the extrusion pressure required and the exit temperature as a combined result of temperature evolution and the friction between the deforming material and the extrusion tooling.

To achieve a high throughput, a maximum extrusion speed is desirable. A too high extrusion speed will, however, cause the exit temperature to exceed a critical value, leading to local melting and surface defects, as the excessive heat evolving from deformation and generated from friction cannot efficiently dissipate through the extrusion tooling [3]. In general, a low billet temperature and a high speed tend to give a good extrudate surface finish [4]. In this case, however, the process requires a high pressure. To run an extrusion cycle successfully, the pressure required should never go beyond the pressure capacity of the press used for the extrusion operation. Therefore, extrusion process optimization to achieve a high throughput and extrudate surface quality concerns the interplay of billet temperature and extrusion speed in relation to the exit temperature and extrusion pressure. In the current industry practice, extrusion process optimization is based on the experience of the press operator, with a lack of the insight into the interactions between the process variables and material response. Physical simulation and on-site measurements offer limited scopes to gain such an insight. Computer simulation based on the finite element (FE) method can provide detailed information to assist in gaining this insight. 
Table 1 Physical properties of the billet material and extrusion tooling material

\begin{tabular}{|c|c|c|}
\hline Properties & AZ31 & H13 \\
\hline Heat capacity $\left[\mathrm{N} / \mathrm{mm}^{2 \circ} \mathrm{C}\right]$ & $\begin{array}{l}2.09684 \text { at } 327^{\circ} \mathrm{C} \\
2.27484 \text { at } 527^{\circ} \mathrm{C}\end{array}$ & 5.6 \\
\hline Thermal conductivity $\left[\mathrm{W} / \mathrm{m}^{\circ} \mathrm{C}\right]$ & 96 & 28.4 \\
\hline Heat transfer coefficient between tooling and billet $\left[\mathrm{N} /{ }^{\circ} \mathrm{C} \mathrm{s} \mathrm{mm}{ }^{2}\right]$ & 11 & 11 \\
\hline Heat transfer coefficient between tooling/billet and air $\left[\mathrm{N} /{ }^{\circ} \mathrm{C} \mathrm{s} \mathrm{mm}{ }^{2}\right]$ & 0.02 & 0.02 \\
\hline Emissivity & 0.12 & 0.7 \\
\hline
\end{tabular}

In recent years, the capabilities of FE simulation to understand the thermomechanics of magnesium extrusion have been well demonstrated. The extrusion behavior of wrought magnesium alloys, such as AZ31, AZ61 and ZK60, was described through two-dimensional FE simulation [5]. To limit the complications of simulation and computational time, the process was assumed to be adiabatic [6], which did not objectively describe the reallife extrusion process.

In the preceding research, three-dimensional computer simulations were performed with thermal effects incorporated, aimed at establishing the relationship between the ram speed and exit temperature in the case of producing a rectangular section with rounded corners [7]. The close agreements between the results from computer simulation and experimentation in extrudate temperature and extrusion pressure indicated the validity of the material date, material model and boundary conditions applied in these simulations. The increase of the extrudate temperature from the initial billet temperature was found to be a linear function of logarithmic ram speed. The research however did not reflect the interplay of billet temperature and ram speed in achieving process optimization.

The present research concerns FE simulation of extrusion to produce a cross-shaped profile with sharp corners whose local temperatures at the die exit would be more sensitive to the extrusion process variables. It was aimed primarily at gaining an understanding of the correlation between the initial billet temperature and the exit temperature through both FE simulation and experimental verification. To demonstrate that this correlation was not unique, but dependent on extrusion speed, ram speed was also varied. A set of the correlations between the initial billet temperature and the exit temperature at various ram speeds could be used as guidelines for extrusion process optimization.

\section{Computer simulation and experimental details}

Materials and geometry

A wrought magnesium alloy AZ31 with 3\% aluminium, 1\% zinc and balance magnesium by weight was used as the billet material both in FE simulation and experimental verification. The extrusion tooling composed of a die, a container and a stem with a dummy block attached was made of the H13 hot-work tool steel. (The other extrusion tooling, i.e. the die backer, bolster and subbolster behind the die was omitted in the FE simulations.) The physical properties of the billet material and extrusion tooling material are listed in Table 1.

Figure 1 shows the cross-section of the extruded profile. To save the computational time for the FE simulation of the process from the transient state to the steady state, only the shaded portion of the object was modelled to take advantage of its symmetry. Artificial symmetrical planes were assumed to be immobile with no material moving across.

Table 2 gives the process parameters used in FE simulation. Both billet temperature and ram speed were taken as process variables. The initial temperature of the extrusion tooling was kept $50^{\circ} \mathrm{C}$ lower than that of the billet to allow heat dissipation.

FE models, material data and boundary conditions

The DEFORM 3D version 5.0 software package was used for FE simulation. Figure 2 shows the FE models of the billet and extrusion tooling with initial meshes. The billet,

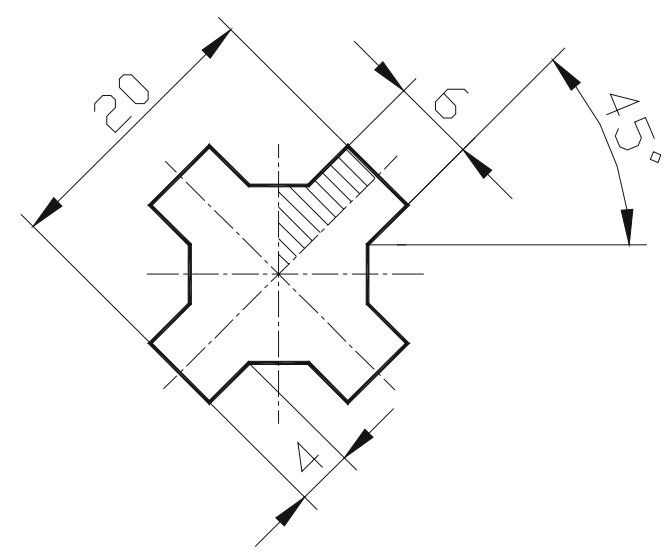

Fig. 1 Cross section of the profile with the shaded area selected for EF simulation 
Table 2 Dimensions of the billet and extrusion tooling and process parameters

\begin{tabular}{lccc}
\hline Billet length $[\mathrm{mm}]$ & 200 & \\
Billet diameter [mm] & 48.8 & \\
Container inside diameter $[\mathrm{mm}]$ & 50 & \\
Container outside diameter $[\mathrm{mm}]$ & 132 & & \\
Reduction ratio & 8.8 & & 450 \\
Die bearing length $[\mathrm{mm}]$ & 5 & & 400 \\
Initial billet temperature $\left[{ }^{\circ} \mathrm{C}\right]$ & 350 & 400 & \\
Initial tooling temperature $\left[{ }^{\circ} \mathrm{C}\right]$ & 300 & 350 & \\
Ram speed $[\mathrm{mm} / \mathrm{s}]$ & $2,4,8$ & & \\
\hline
\end{tabular}

container, die and stem were meshed with tetrahedral elements. The detailed information about the element density and remeshing trigger is given in [7]. The billet was considered thermo-viscoplastic such that its deformation behaviour was a function of temperature, strain rate and strain. A thermo-viscoplastic material model was converted into a numerical formulation and implemented in FE analysis within the DEFORM software package. A thermo-rigid material model was applied to the extrusion tooling. Both of these material models neglected the elastic behaviour of the materials. Heat exchanges between the billet, extrusion tooling and atmosphere were incorporated into the models within the DEFORM software package that took the three modes of heat transfer (conduction, convection and radiation) into account. The heat transfer coefficients were taken from the User's Manual of the DEFORM software package.

True flow stress-strain data of the AZ31 alloy needed for the thermo-viscoplastic material model were determined through hot compression tests over a range of temperatures from 300 to $500^{\circ} \mathrm{C}$ and a range of strain rates from $0.03 \mathrm{~s}^{-1}$ to $90 \mathrm{~s}^{-1}$ and to a true strain of 1 . The flow stress data obtained were then corrected for deformation heating

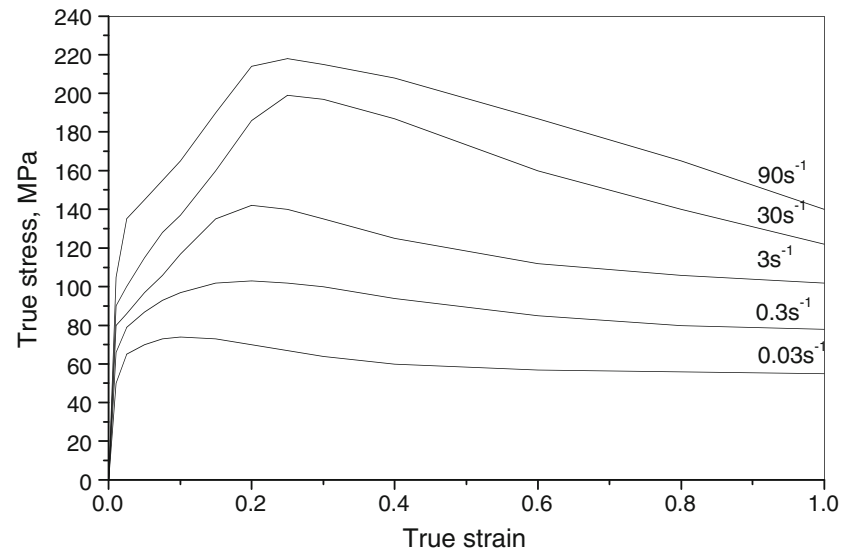

Fig. 3 True stress/true strain curves of AZ31 obtained from hot compression tests at $300^{\circ} \mathrm{C}$ and corrected for deformation heating during the testing

during hot compression [8]. The corrected flow stresses as a function of strain, strain rate and temperature were used as input material data. Figure 3 shows a set of flow stress/ strain curves as examples. Constant shear friction was considered appropriate for the description of the interfacial friction during magnesium extrusion. The frictional force in the constant shear model is defined as $f_{s}=m k$, where $f_{s}$ is the frictional stress, $\mathrm{k}$ the shear yield stress and $\mathrm{m}$ the friction factor. In the present study, a friction factor of 1.0 was chosen at the interfaces between the billet and container and between the billet and stem to reflect the strong adhesion of hot magnesium to extrusion tooling made of the tool steel H13, according to the results of the ring upsetting tests of the AZ31 magnesium alloy at elevated temperatures [9]. The friction condition at the billet/die face interface and at the billet/ die bearing interface was simplified by neglecting the slipping contact at the die outlet, but considering only the sticking contact at the die face and at the die inlet where the friction exceeded
Fig. 2 FE models of the billet and extrusion tooling to produce the cross-shaped profile as illustrated in Fig. 1
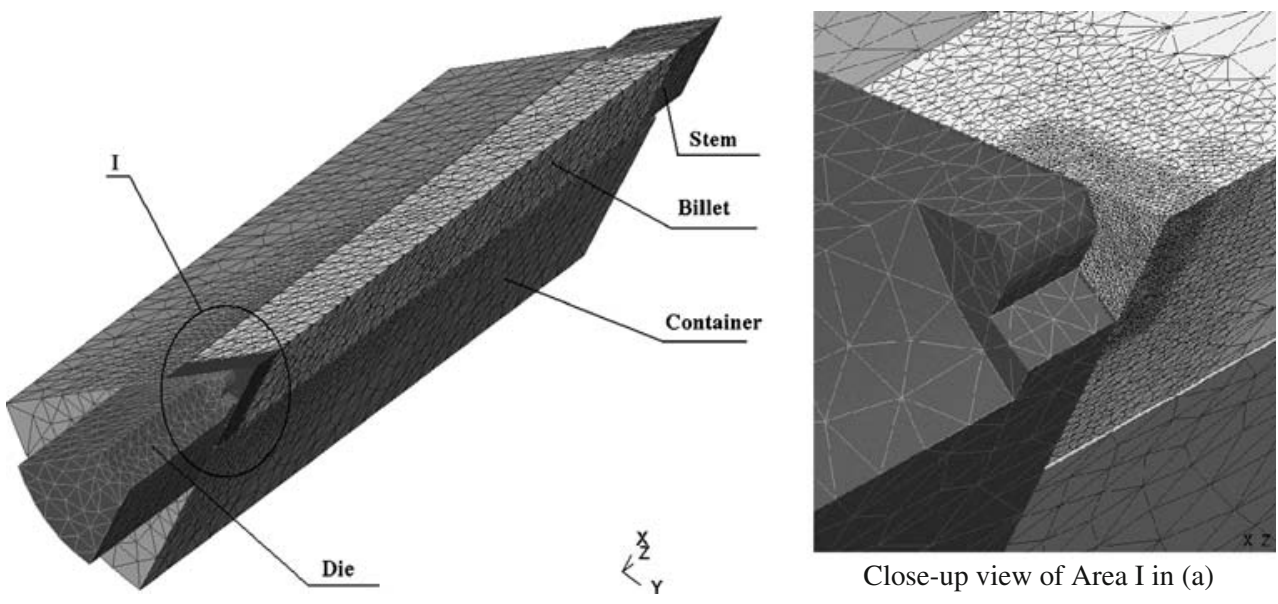

Close-up view of Area I in (a) 
the shear strength of the deforming billet. The overall friction factor at these interfaces was overestimated to be 1.0 .

\section{Extrusion experiments}

The verification of the results obtained from FE simulation was realized through real-life extrusion. To produce the cross-shaped profile as shown in Fig. 1, a flat-faced die with a uniform bearing length of $5 \mathrm{~mm}$ was designed. A fully instrumented $2.5 \mathrm{MN}$ extrusion press was employed. The initial billet temperature, die temperature and container temperature were desired to be identical to those in the FE simulations as given in Table 2. In experiments, however, extrusion was carried out in the billet-to-billet manner as in the industrial practice, instead of waiting for the tooling temperature after one extrusion cycle to return to the desired temperature for the next extrusion cycle. As a result, the initial temperature difference of $50^{\circ} \mathrm{C}$ between the billet and extrusion tooling was gradually vanished after a few extrusion cycles. A 3T multi-wavelength pyrometer with a spot size of $10 \mathrm{~mm}$ was placed at $200 \mathrm{~mm}$ behind the die exit in order to avoid the radiations from the die heated by a band-type resistance heater from disturbing the measurement of the exact temperature of the profile. After exiting from the die, the profile travelled through a backer, a bolster and a subbolster that were situated behind the heated die and then entered a tube with an inside diameter of $38 \mathrm{~mm}$. The heat loss during the travel over a distance of $200 \mathrm{~mm}$ through the die stack and the tube was considered insignificant, as indicated by the good agreement between the FE simulation results and pyrometer measurements [7]. Extrusion pressure, ram displacement, ram speed, die temperature, container temperature and extrudate tempera-

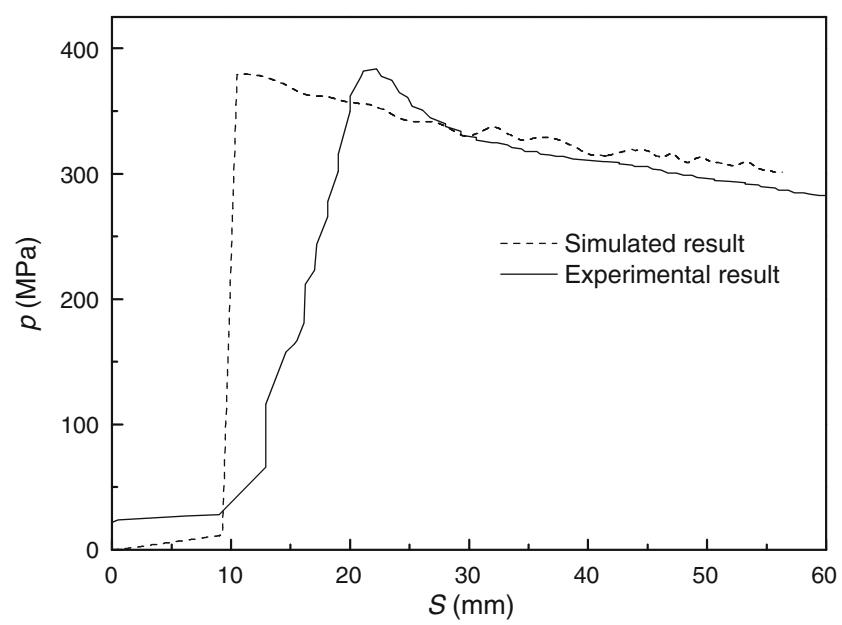

Fig. 4 Extrusion pressure/ram displacement diagrams of extrusion at a ram speed of $2 \mathrm{~mm} / \mathrm{s}$

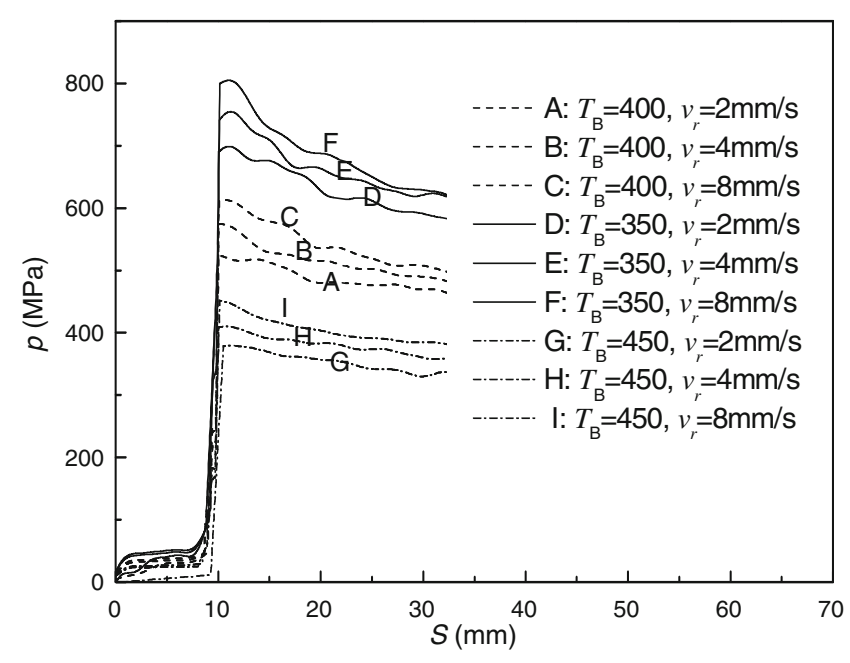

Fig. 5 Predicted pressure evolutions at different ram speeds and billet temperatures

ture were displayed in real time during the process and saved for post-extrusion data processing.

\section{Results and discussion}

Effect of billet temperature on extrusion pressure

Of main interest is the effect of the initial billet temperature on the breakthrough pressure (or the peak pressure) of the extrusion process, because this pressure decides if extrusion can be run successfully. Figure 4 compares the extrusion pressure/ram displacement diagrams obtained from $\mathrm{FE}$ simulation and experiments, when ram speed was $2 \mathrm{~mm} / \mathrm{s}$. It can be seen that the breakthrough pressure predicted from FE simulation is quite close to the value measured. The difference is however that in real extrusion the breakthrough occurs later during an extrusion cycle, as a result of the elastic deformation of the billet and extrusion tooling, which was neglected altogether during the FE simulation.

Figure 5 shows the predicted extrusion pressure/ram displacement diagrams at different billet temperatures and ram speeds. It is clear that the breakthrough occurs at a similar ram displacement, although ram speeds differ considerably (from $2 \mathrm{~mm} / \mathrm{s}$ to $8 \mathrm{~mm} / \mathrm{s}$ ). The breakthrough pressure varies greatly with billet temperature. A $100^{\circ} \mathrm{C}$ increase in billet temperature from $350^{\circ} \mathrm{C}$ to $450^{\circ} \mathrm{C}$ leads to a $100 \%$ decrease in the breakthrough pressure. The breakthrough pressure also increases with increasing ram speed, but the magnitude of increase is insignificant; at a certain billet temperature, it increases by only $15 \%$, when ram speed increases from $2 \mathrm{~mm} / \mathrm{s}$ to $8 \mathrm{~mm} / \mathrm{s}$. Therefore, to prevent the breakthrough pressure from exceeding the 
Fig. 6 Iso-surfaces of temperature in the deforming billet during extrusion $\left(v_{r}=2 \mathrm{~mm} / \mathrm{s}\right)$

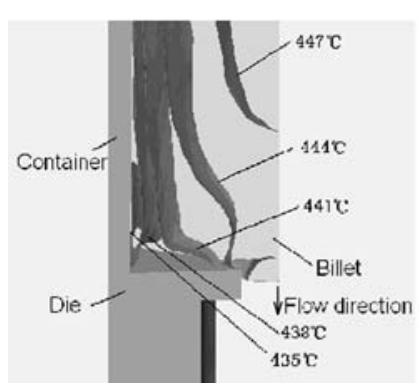

(a) $S=10 \mathrm{~mm}$

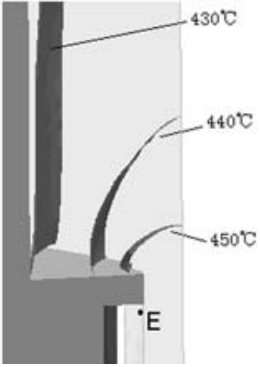

(b) $S=16 \mathrm{~mm}$

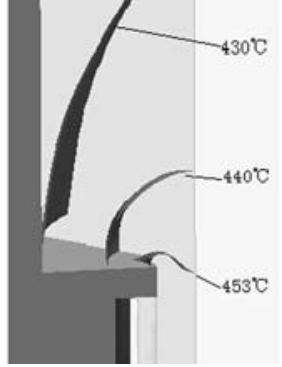

(c) $S=21.2 \mathrm{~mm}$

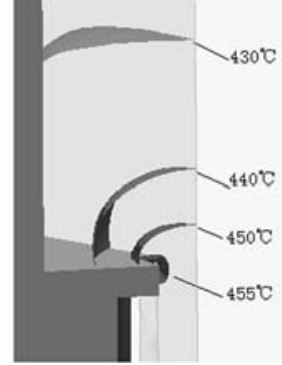

(d) $S=60 \mathrm{~mm}$ maximum pressure of the press, adjusting billet temperature is more effective. In other words, within a small margin below the maximum extrusion pressure of the press, there is a considerable scope to increase extrusion speed and to maximize the throughput of extrusion, as long as the exit temperature does not reach the incipient melting point of the billet material.

Evolution of the temperatures in the billet during extrusion

Figure 6 shows iso-temperature surfaces in the billet during extrusion at a ram speed of $2 \mathrm{~mm} / \mathrm{s}$ and an initial billet temperature of $450^{\circ} \mathrm{C}$. At the beginning of the extrusion cycle over a ram displacement from $10 \mathrm{~mm}$ to $16 \mathrm{~mm}$ (Fig. 6a, b) when the process was in the transient state, the temperatures of the billet in contact with the container decrease from $450^{\circ} \mathrm{C}$ to $430^{\circ} \mathrm{C}$, as a result of heat loss to the container and through the container to the surroundings. The initial container temperature was $50^{\circ} \mathrm{C}$ lower than the billet temperature and thus the container acted as if it was a heat sink. However, the temperatures of the billet in front of the die face increase gradually as the deformation zone forms. The maximum temperature appears at the junction

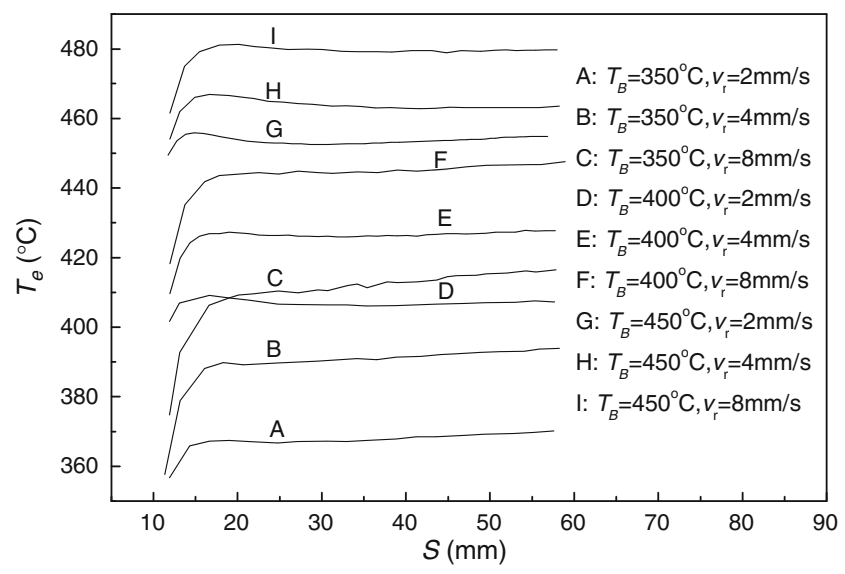

Fig. 7 Predicted extrudate temperature at the die exit during extrusion at different billet temperatures and ram speeds between the die bearing and die face where severe shear and friction occur. Near the rear end of the billet, temperature decreases as a result of the backflow of the colder material from the periphery of the billet, in addition to the heat loss to the stem.

\section{Evolution of the exit temperature during extrusion}

The simulated extrudate temperatures at the die exit (i.e. point $\mathrm{E}$ indicated in Fig. $6 \mathrm{~b}$ ) during the extrusion cycles at different billet temperatures and ram speeds are shown in Fig. 7. It is clear that the extrudate temperature increases quickly at the transient stage of extrusion, i.e. over a short ram displacement range from $10 \mathrm{~mm}$ to $16 \mathrm{~mm}$. The lower the initial billet temperature, the higher the temperature rises during the transient extrusion. In addition, ram speed has a pronounced effect on the initial temperature rise. A higher ram speed leads to a larger initial temperature rise. The thermal effects are stronger when the initial billet temperature is lower. After reaching a ram displacement of $16 \mathrm{~mm}$, the process enters the steady-state stage and the exit temperature tends to be stable. As the initial billet temperature increases, it becomes closer to being constant

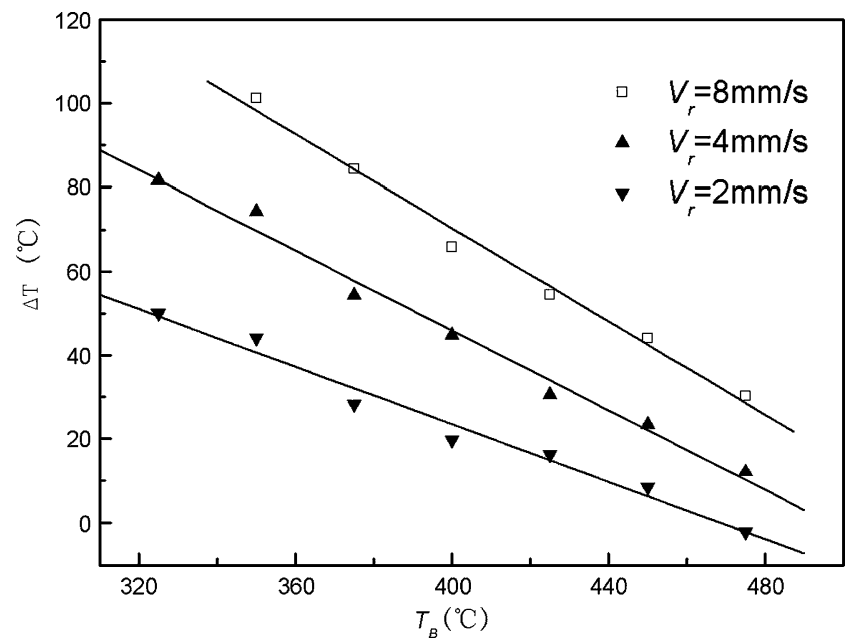

Fig. 8 Measured temperature rises at a ram displacement of $60 \mathrm{~mm}$ 
and the process is nearer to an isothermal one. In all the cases, the temperature values of the extrudates in the steady state are quite similar to those at the end of the transient state. Therefore, the thermal effects in the transient state dictate the choice of the process variables. For a nearly constant exit temperature during most of an extrusion cycle (near isothermal extrusion), one may choose the combination of a higher billet temperature and a lower ram speed or the combination of a lower billet temperature and a higher ram speed. As stated earlier, in the case of the extrusion of the AZ31 magnesium alloy, the breakthrough pressure is not highly sensitive to ram speed. Thus, the combination of a low billet temperature and a high speed is a more sensible choice, which will lead to a higher throughput.

It is important to mention that the predicted extrudate temperatures given in Fig. 7 are considerably lower than those from the extrusion experiments as shown below. The main reason is that in the $\mathrm{FE}$ simulations a temperature difference of $50^{\circ} \mathrm{C}$ between the billet and extrusion tooling allowed for heat dissipation from the deforming billet to the extrusion tooling, resulting in limited temperature increase of the extrudate at the die exit. In extrusion experiments, however, the process was carried out in the billet-to-billet semi-continuous fashion, the temperature difference between the billet and extrusion tooling became much smaller, with extrusion experiments proceeding, allowing for less heat dissipation and resulting in more temperature rise of the extrudate.

\section{Effect of billet temperature on temperature rise}

The temperature rise from the initial billet temperature $T_{B}$ to the extrudate temperature $T_{P}$ at a given ram displacement is an important parameter. It allows the press operator to select an appropriate billet temperature and to ascertain in advance that the exit temperature will not reach the incipient melting temperature. Figure 8 shows the temperature rises from different initial billet temperatures, when ram displacement is at $60 \mathrm{~mm}$. It can be seen that at all the ram speeds, the relationship between the temperature rise and billet temperature is approximately linear. As ram speed increases, the slope increases, because of larger thermal effects and less time for heat dissipation. At a ram speed of $8 \mathrm{~mm} / \mathrm{s}$, for example, the relationship may be expressed as:

$\Delta T=293.3-0.56 T_{B}$

where $\Delta T$ is the temperature rise from the initial billet temperature $T_{B}$, namely $\Delta T=T_{p}-T_{B}$. With this relationship established, the initial temperature can easily be chosen as long as the maximum permissible temperature of the billet material is known:

$T_{B}=\left(T_{P}-293.3\right) / 0.44$

If an exit temperature of $500^{\circ} \mathrm{C}$ is metallurgically permitted and a high extrusion speed is desired, a billet temperature of $470^{\circ} \mathrm{C}$ may be used for billet preheating. To make the relationship of practical use, the experimentally measured $T_{p}$ was used in Fig. 8 and Eq. 2.

\section{Conclusions}

The three-dimensional EF simulation of the extrusion process to produce a cross-shaped AZ31 profile and the extrusion experiments performed lead to the following conclusions.

(1) The initial billet temperature has a greater influence on the breakthrough pressure than ram speed. It also plays an important role in determining the exit temperature and the temperature rise, especially when ram speed is high. With the combination of a high billet temperature and a low ram speed, near isothermal extrusion can be realized. With the combination of a low billet temperature and a high ram speed, a high throughput can be achieved.

(2) At a given ram speed, the relationship between the temperature rise and billet temperature is linear. The selection of an optimum billet temperature can be based on the desirable ram speed and the metallurgically permitted exit temperature of the deforming material, as long as the press pressure capacity is not exceeded.

Acknowledgements Thanks are due to Mr. M.A. Leeflang for performing extrusion experiments to validate the results obtained from FE simulation and to Mr. L.L. Wang and Mr. K. Huang for postprocessing of simulation data.

Open Access This article is distributed under the terms of the Creative Commons Attribution Noncommercial License which permits any noncommercial use, distribution, and reproduction in any medium, provided the original author(s) and source are credited.

\section{References}

1. Kaibyshev RO, Sitdikov OSh, Galiev AM (1995) Mechanisms of plastic deformation in magnesium: II Analysis of activation processes. Phys Met Metallogr 80:470-475

2. Sheppard T (1981) Temperature and speed effects in hot extrusion of aluminium alloys. Met Technol 8:130-141 
3. Lapovok RYe, Barnett MR, Davies CHJ (2004) Construction of extrusion limit diagram for AZ31 magnesium alloy by FE simulation. J Mater Process Technol 146:408-414

4. Emley EF (1966) Principles of magnesium technology. Pergamon, Oxford

5. Ogawa N, Shiomi M, Osakada K (2002) Forming of magnesium alloy at elevated temperatures for precision forming. Int $\mathrm{J}$ Mach Tool Manu 42:607-614

6. Chandrasekaran M, John YMS (2004) Effect of materials and temperature on the forward extrusion of magnesium alloys. Mater Sci Eng A 381:308-319
7. Liu G, Zhou J, Duszczyk J (2007) Prediction and verification of temperature evolution as a function of ram Speer during the extrusion of AZ31 alloy into a rectangular section. J Mater Process Technol 186:191-199

8. Li L, Zhou J, Duszczyk J (2006) Determination of a constitutive relationship for AZ31B magnesium and validation through comparison between simulated and real extrusion. J Mater Process Technol 172:372-380

9. Doege E, Janssen ST, Wieser J (2001) Kennwerte für die magnesiumumformung am beispiel van AZ31. Mater wiss Werkst tech $32: 48-51$ 